Article

\title{
Putting the Pieces Together: Mental Construction of Semantically Congruent and Incongruent Scenes in Dementia
}

\author{
Nikki-Anne Wilson ${ }^{1,2,3,4}\left(\mathbb{D}\right.$, Rebekah M. Ahmed ${ }^{1,5}$, Olivier Piguet ${ }^{1,2}$ and $^{-}$auireann Irish ${ }^{1,2, *(\mathbb{D})}$ \\ 1 Brain and Mind Centre, The University of Sydney, Sydney, NSW 2050, Australia; \\ n.wilson@neura.edu.au (N.-A.W.); rebekah.ahmed@sydney.edu.au (R.M.A.); \\ olivier.piguet@sydney.edu.au (O.P.) \\ 2 School of Psychology, The University of Sydney, Sydney, NSW 2006, Australia \\ 3 School of Psychology, The University of New South Wales, Sydney, NSW 2052, Australia \\ 4 Neuroscience Research Australia, Sydney, NSW 2031, Australia \\ 5 Memory and Cognition Clinic, Institute of Clinical Neurosciences, Royal Prince Alfred Hospital, \\ Sydney, NSW 2050, Australia \\ * Correspondence: muireann.irish@sydney.edu.au
}

Citation: Wilson, N.-A.; Ahmed, R.M.; Piguet, O.; Irish, M. Putting the Pieces Together: Mental Construction of Semantically Congruent and Incongruent Scenes in Dementia. Brain Sci. 2022, 12, 20. https:// doi.org/10.3390/brainsci12010020

Academic Editors: Vasileios

Papavasileiou and Ana Maria Bugă

Received: 1 December 2021

Accepted: 21 December 2021

Published: 24 December 2021

Publisher's Note: MDPI stays neutral with regard to jurisdictional claims in published maps and institutional affiliations.

Copyright: (c) 2021 by the authors. Licensee MDPI, Basel, Switzerland. This article is an open access article distributed under the terms and conditions of the Creative Commons Attribution (CC BY) license (https:// creativecommons.org/licenses/by/ $4.0 /)$.

\begin{abstract}
Scene construction refers to the process by which humans generate richly detailed and spatially cohesive scenes in the mind's eye. The cognitive processes that underwrite this capacity remain unclear, particularly when the envisaged scene calls for the integration of various types of contextual information. Here, we explored social and non-social forms of scene construction in Alzheimer's disease (AD; $n=11)$ and the behavioural variant of frontotemporal dementia (bvFTD; $n=15)$ relative to healthy older control participants $(n=16)$ using a novel adaptation of the scene construction task. Participants mentally constructed detailed scenes in response to scene-object cues that varied in terms of their sociality (social; non-social) and congruence (congruent; incongruent). A significant group $\times$ sociality $\times$ congruence interaction was found whereby performance on the incongruent social scene condition was significantly disrupted in both patient groups relative to controls. Moreover, bvFTD patients produced significantly less contextual detail in social relative to non-social incongruent scenes. Construction of social and non-social incongruent scenes in the patient groups combined was significantly associated with independent measures of semantic processing and visuospatial memory. Our findings demonstrate the influence of schema-incongruency on scene construction performance and reinforce the importance of episodic-semantic interactions during novel event construction.
\end{abstract}

Keywords: scene construction; schema; semantic memory; episodic memory; frontotemporal dementia; imagination; social cognition

\section{Introduction}

Scene construction refers to the capacity to generate and maintain a richly detailed, spatially cohesive mental scene, and relies on coordinated activity within a distributed brain network centred on the hippocampus [1-3]. Previous reports have identified associations between scene construction and autobiographical memory [4], future thinking [5], and navigation [6]. Theory of Mind (ToM), or mentalising, has also been theorised to depend on the content and phenomenological quality of mentally constructed scenes [7]. Collectively, these findings have garnered support for the view that scene construction forms the foundation for an array of higher-order complex constructive endeavours [8]. While significant advances have been made in delineating the neural bases of scene construction, comparatively less is known regarding the cognitive processes that underwrite this capacity, particularly when the envisaged scene calls for the integration of various types of contextual information. 
Episodic memory and scene construction are closely connected, as reflected by the significant overlap of their neural substrates $[1,5]$ and parallel impairments observed in clinical populations ([9], but see [10]). By contrast, less is known regarding the potential role of semantic memory in the construction of mental scenes. Initial evidence from developmental amnesic patients hinted at the possibility that a residual capacity for scene construction is supported by intact semantic memory [11,12]. These findings have led to greater consideration of the role of conceptual knowledge in the constructive endeavour $[8,13,14]$. Empirical demonstrations of the pivotal role of semantic memory in past and future forms of mental construction [15] have further fuelled the debate regarding the interplay between episodic and semantic elements during mental construction [16-18]. Accordingly, semantic memory is proposed to provide the requisite scaffold or organisational framework to guide retrieval of past events, the simulation of future scenarios, and the mental representation of spatially coherent scenes $[16,19]$. With an appropriate semantic framework in place, details from episodic experiences, along with conceptual information, and event scripts can then be assimilated into the simulation to create a detailed and spatially integrated mental representation $[14,18]$.

Another way by which semantic memory may support the constructive endeavour is in supporting knowledge manipulation and generalisation during the construction of new experiences [20]. Indeed, this form of conceptual association is well-documented in the creativity literature, enabling access to relevant conceptual information and the ability to draw appropriate links between concepts to generate novel ideas [21]. In this regard, semantic elements or objects - their number, form, and their inter-relationships-appear to heavily moderate how a mental scene is constructed. For example, envisaging three objects within a three-dimensional space is sufficient to evoke the subjective experience of a real-world scene [22]. In contrast, mentally generating three objects within a twodimensional space fails to evoke the same subjective experience of a scene [23]. The nature of an object also contributes to how a scene is constructed, with space-defining objects (e.g., a wooden rocking chair) more central and evoking a greater sense of spatial context than space-ambiguous objects (e.g., a folded newspaper; [24]). As such, the relationship between scenes and objects, and the conceptual categories they invoke, plays a significant role in the way in which a mental scene is constructed and subjectively experienced.

Objects are, of course, not the only items that define a scene. The social nature of scenes, for example, requires the curation, selection, and integration of social elements, i.e., people, into the spatial array $[25,26]$. If different objects evoke different levels of spatial context, the inclusion of people, as a social class of object, likely requires the added consideration of the thoughts and emotions of an envisaged person, as well as their actions and interactions within the scene [25]. Envisaging social scenes has been shown to more heavily draw upon previous experience than constructing non-social scenes [26], resonating with suggestions of a foundational role for episodic memory in prosocial behaviour [27].

Finally, it is important to consider whether scene and object information is congruent with pre-existing knowledge structures. Schemas are superordinate knowledge structures that extract commonalities across events and experiences [28] and are suggested to provide the necessary framework from which a scene is created $[29,30]$. Once activated, schema templates influence how incoming information is processed whereby congruent information is prioritised and strengthened, while incongruent information may be deemed inconsequential and discarded [28]. Empirical studies in healthy adults indicate that information that is congruent with existing schemas is recognised and recollected more accurately and more quickly relative to incongruent information (reviewed by [31]). How schema incongruency influences the construction and quality of mental scenes remains unclear.

Given these intersecting lines of enquiry, the current study sought to explore how object-scene (in)congruency impacts the capacity for scene construction in dementia syndromes characterised by variable impairments in scene construction, semantic memory, and social cognition. The behavioural variant of frontotemporal dementia (bvFTD) is a younger-onset neurodegenerative disorder characterised by profound changes in person- 
ality and behaviour, executive dysfunction, and disinhibition, resulting in severe socioemotional dysfunction [32,33]. We have previously demonstrated that patients with bvFTD exhibit profound impairments in the construction of future scenarios [34] and commonplace scenes [35], which is exacerbated when the scene calls for the integration of social information [26]. In contrast, patients with Alzheimer's disease (AD) typically present with episodic memory disturbances alongside visuospatial dysfunction and, to a lesser extent, semantic processing difficulties [36]. Recent studies indicate marked impairments in AD across an array of constructive processes including future thinking [37,38] and scene construction [39] in the context of relatively preserved social cognition [40,41]. Given these differential profiles of loss and sparing, these syndromes provide a unique opportunity to explore the integration of semantically congruent and incongruent objects within scene arrays that vary in terms of their social nature. As such, we manipulated the semantic congruency of object-scene pairings along with the sociality of the to-be-constructed scene with the hypothesis that incongruency would disrupt the constructive endeavour most prominently for social scenes in bvFTD.

\section{Materials and Methods}

\subsection{Participants}

Fifteen individuals with a clinical diagnosis of probable bvFTD and 11 individuals with typical Alzheimer's disease (AD) were contrasted with 16 healthy older control participants. Briefly, clinical presentation of bvFTD included progressive behavioural and/or personality changes including inappropriate behaviour, apathy, reduced empathy, perseverative behaviour and/or executive dysfunction [32]. Conversely, AD patients presented with significant episodic memory, visuospatial, and language (particularly word-finding) difficulties, in the context of relatively intact social behaviour [36]. Participants were recruited through FRONTIER, the frontotemporal dementia research group based at the Brain and Mind Centre, The University of Sydney. Dementia diagnosis was based on multidisciplinary consensus incorporating clinical history, cognitive profile, and neuroimaging. Previous neurological or neuropsychiatric conditions, substance abuse or a lack of proficiency in English precluded participation in the study. Dementia patients were excluded if they achieved a score lower than 40 on the Addenbrooke's Cognitive Examination III (ACE-III) due to the severity of their cognitive impairment. Control participants were required to score $>88$ on the ACE-III. The Frontotemporal Lobar Degeneration-modified Clinical Dementia Rating scale (CDR-FTLD) Sum of Boxes score [42] was used as an index of disease severity, while the Cambridge Behavioural Inventory-Revised (CBI-R) [43] provided a measure of behavioural changes, as rated by the informant.

\subsection{Cognitive Assessment}

All participants completed a comprehensive neuropsychological battery assessing the main cognitive domains as well as global cognitive function (ACE-III; [44,45]). Verbal episodic memory was assessed using the Rey Auditory Verbal Learning Test (RAVLT; [46]), while nonverbal episodic memory was measured using the 3 min delayed recall of the Rey Complex Figure (RCF; [47]). Language abilities were evaluated using targeted assessments of naming, comprehension, and semantic association from the Sydney Language Battery (SydBAT; [48]). Measures of executive function included Digit Span Forwards and Backwards [49] to index attention and working memory, respectively, as well as the time difference between parts B and A on the Trail Making Test (TMT; [50]) and the scaled score on the Hayling Sentence Completion Test [51].

\subsection{Scene Construction Task}

A modified version of the scene construction task [52] was used with sociality and congruence manipulated. Briefly, participants imagined and described aloud atemporal scenes in as much detail as possible, avoiding restating a memory. Each scene cue contained a background setting and a person or object, dependent on the level of sociality (i.e., people 
in the social conditions, objects in the non-social conditions). The background setting was either congruent or incongruent with the person or object. Congruent trials included hospital (background scene) and doctor (person, social); and classroom (background scene) and books (object, non-social). Congruency was informed by ratings of which items were most likely to go together from pilot testing in a sample of healthy young adults $(N=10$; see Supplementary Material). Incongruent trials represented combinations least likely to go together, including funeral (background scene) and clown (person, social); and beach (background scene) and ice-skates (object, non-social). A $2 \times 2$ design was used exploring Congruency (congruent, incongruent) and Sociality (social, non-social). To minimise risk of fatigue and cognitive demand in dementia patients, each scene description was limited to $2 \mathrm{~min}$. Congruent and incongruent trials were completed in a blocked design, with order of blocks counterbalanced across participants.

The current study used succinct scene cues, which were standardised in syntactic structure (e.g., "You're at a funeral. There is a clown there") across conditions to limit cognitive demand and the possibility of unintentionally probing inter-item relationships. Participants were instructed to make sure to include both elements (i.e., object/person and background) into a coherent scene description, "Even if the two things don't feel like they belong together at all, I want you to try really hard to create as believable a scenario as possible including both the background setting and the person or object." An example of an incongruent scene was provided (Office Boardroom and Hairdryer) whereby the experimenter confirmed with the participant that the two example elements did not go together but then pretended to complete the task while reciting a standardised scene description. Cues were read aloud and presented on a sheet of paper, which remained in front of participants for the duration of the trial to minimise working memory demands. General prompts were provided to encourage elaboration or if the participant failed to include the two scene elements (see Supplementary Material for the example scene and prompts). Importantly, these prompts were non-directive, limited to two per scene and merely served to encourage the participant to provide additional details. For example, "Remembering to include both the $\mathrm{X}$ and the $\mathrm{Y}$ in the scenario that you're describing, are there any other details you can tell me?" The entire test session lasted approximately 25-30 min and was digitally recorded for subsequent transcription and scoring.

\subsection{Subjective Ratings}

In keeping with the original Hassabis et al. protocol [52], following each scene description, participants were asked to rate the constructed scene in terms of perceived difficulty, vividness, level of detail, sense of presence, and similarity to a previous memory. An additional rating was included to capture the subjective degree to which the two elements were realistically integrated into a coherent scene, "How realistic did the scene feel to you?", rated on a scale from 1 to 5 , with higher ratings indicating a stronger sense of realism.

\subsection{Scoring}

Total Content scores represented the primary measure of scene construction performance. Scene transcripts were segmented into discrete contextual detail types: (i) Entities Present, (ii) Sensory Descriptions, (iii) Spatial References, and (iv) Thoughts/Emotions / Actions (see [52] for full scoring details). The maximum number of details for each subcategory was capped at 7 points, leading to a maximum Total Content score of 28, in keeping with the original scene construction scoring protocol [52].

\subsection{Statistical Analyses}

Data were analysed using IBM SPSS version 26 . For continuous variables, normality of distributions was examined using Kolmogorov-Smirnov tests. Group differences for normally distributed continuous variables (e.g., age at assessment, years of education) were assessed using univariate ANOVAs. Group differences on categorical variables (e.g., sex) were examined using Chi-squared tests. Where limited cognitive data resulted in small 
and uneven sample sizes, or data were non-normally distributed (e.g., participant subjective ratings), non-parametric Kruskal-Wallis tests for independent samples and Wilcoxon signed-rank tests for related samples were used. Group differences on the scene construction task were assessed via a mixed $3 \times 2 \times 2$ ANOVA with group (Control, AD, bvFTD) as the between-subjects factor, and congruency (congruent, incongruent) and sociality (social, non-social) as the within-subject factors. For ease of interpretation, and due to no main effect of congruency being found, two mixed $3 \times 2 \times 4$ ANOVAs were performed in the incongruent and congruent conditions separately with group as the between-subjects factor, and sociality (social, non-social) and contextual detail category (Entities Present, Sensory Descriptions, Spatial References and Thoughts/Emotions/Actions) as the within-subject factors. Post hoc comparisons were adjusted using Bonferroni correction where appropriate; however, due to the exploratory nature of the study, where extensive comparisons would have resulted in overly conservative Bonferroni correction (e.g., subjective ratings, correlations with cognitive variables), uncorrected values are reported. The alpha level to determine statistical significance was set at $p<0.05$. Partial eta-squared values $\left(\eta_{\mathrm{p}}^{2}\right)$ were assessed as a measure of effect size for ANOVA statistics.

\section{Results}

\subsection{Demographic and Clinical Information}

Age at assessment, $\mathrm{F}(2,39)=1.0 ; p=0.393 ; \eta_{\mathrm{p}}^{2}=0.05$, and sex distribution, $\chi^{2}(2,42)=5.15$; $p=0.076$, did not differ significantly across Control, AD and bvFTD groups (Table 1). Years of education, however, differed significantly across groups, $\mathrm{F}(2,38)=8.03 ; p=0.001 ; \eta_{\mathrm{p}}{ }^{2}=0.30$, driven by higher levels of education in Controls relative to the two dementia syndromes (both $p$ values $\leq 0.038$ ). Level of education was comparable between the two patient groups $(p=0.707)$. Controlling for years of education did not change the significant three-way interaction for Total Content scores and, thus, education was not considered further in the analyses. Disease severity (CDR-FTLD SoB) and duration (years from symptom onset), $\mathrm{t}(21)=1.57$, $p=0.131$, were comparable between the two patient groups (both $p$ values $>0.13$ ). Finally, a significant group effect for overall behavioural change was found (CBI-R), $\mathrm{F}(2,36)=21.32$; $p \leq 0.0001 ; \eta_{\mathrm{p}}{ }^{2}=0.54$. Bonferroni-adjusted post hoc tests showed comparable overall carerrated behavioural changes in the patient groups $(p=0.517)$; however, bvFTD patients were rated as exhibiting more abnormal behaviours relative to the $\operatorname{AD}$ group $(p=0.046)$.

Table 1. Demographics and clinical characteristics of study participants.

\begin{tabular}{|c|c|c|c|c|c|}
\hline & $\begin{array}{l}\text { bvFTD } \\
\text { M (SD) }\end{array}$ & $\begin{array}{c}\mathrm{AD} \\
\mathrm{M}(\mathrm{SD})\end{array}$ & $\begin{array}{l}\text { Controls } \\
\text { M (SD) }\end{array}$ & $\begin{array}{l}\text { Group Effect } \\
\text { (F Value) }\end{array}$ & $\begin{array}{c}\text { Post hoc } \\
\text { (Direction of Effect) }\end{array}$ \\
\hline $\mathrm{N}$ & 15 & 11 & 16 & - & - \\
\hline Sex (M:F) & $13: 2$ & $6: 5$ & $8: 8$ & $5.1^{\mathrm{a}}$ & - \\
\hline Age (years) & $61.4(9.1)$ & $64.7(8.4)$ & $64.7(4.4)$ & 1.0 & - \\
\hline Education (years) & $11.7(2.0)$ & $12.6(2.6)$ & $14.9(2.2)$ & $8.0 * *$ & $\mathrm{CN}>\mathrm{AD}, \mathrm{bvFTD}$ \\
\hline Disease Duration (years) & $6.7(3.5)$ & $4.6(2.8)$ & - & $0.7^{\mathrm{b}}$ & - \\
\hline $\begin{array}{l}\text { Disease Severity } \\
\text { (CDR-FTLD SoB) }\end{array}$ & $6.3(3.6)$ & $6.8(3.3)$ & - & $1.6^{b}$ & - \\
\hline $\begin{array}{l}\text { Behavioural Change } \\
\text { (CBI-R Total) }\end{array}$ & $38.5(16.7)$ & 30.9 (17.1) & $5.0(4.0)$ & $21.3^{* * *}$ & $\mathrm{AD}, \mathrm{bvFTD}>\mathrm{CN}$ \\
\hline $\begin{array}{l}\text { Abnormal Behaviour } \\
\text { (CBI-R Sub-scale) }\end{array}$ & $40.6(22.2)$ & $20.8(22.7)$ & $3.2(4.2)$ & $14.3^{* * *}$ & bvFTD $>\mathrm{AD}>\mathrm{CN}$ \\
\hline
\end{tabular}

Notes. ${ }^{a}$ Chi-square value. ${ }^{\mathrm{b}}$ Independent samples $t$-test. $\mathrm{M}=$ mean, $\mathrm{SD}=$ standard deviation. Corrected post hoc comparisons are reported. ${ }^{* *}=p<0.01,{ }^{* * *}=p<0.0001$. bvFTD = behavioural-variant frontotemporal dementia; $\mathrm{AD}=$ Alzheimer's disease $\mathrm{CN}=$ Controls; CDR-FTLD SoB = Frontotemporal Lobar Degeneration-Modified Clinical Dementia Rating Sum of Boxes score; CBI-R = Cambridge Behavioural Inventory-Revised. Years of Education data unavailable for 1 Control. CBI-R data unavailable for 3 Controls. Disease duration data unavailable for $2 \mathrm{AD}$ and 1 bvFTD.

\subsection{Cognitive Profiles}

Relative to Controls, bvFTD and AD patients displayed characteristic cognitive deficits largely in keeping with their clinical diagnoses (Table 2). Significant group effects emerged 
across all cognitive variables (all $p$ values $\leq 0.007$ ) with patients scoring significantly worse than Controls for response inhibition and working memory (Hayling, bvFTD, $p=0.013, \mathrm{AD}$, $p \leq 0.0001$; Digit Span Backwards, bvFTD, $p=0.039, \mathrm{AD}, p=0.001)$, delayed verbal episodic memory (RAVLT $30 \mathrm{~min}$, bvFTD, $p=0.001$, AD, $p<0.0001$ ), and verbal fluency (bvFTD, $p=0.001, \mathrm{AD}, p \leq 0.0001)$. Compared to Controls, both patient groups showed significant deficits in overall language ability (ACE Language, bvFTD, $p=0.006$, AD, $p \leq 0.0001$ ), with semantic association (bvFTD, $p=0.243, \mathrm{AD}, p \leq 0.0001$ ) and naming (bvFTD, $p=0.145$, $\mathrm{AD}, p \leq 0.0001)$ impairments on the SydBat occurring exclusively in the AD group. AD patients further displayed marked visuospatial episodic memory dysfunction (RCF $3 \mathrm{~min}$, $p \leq 0.0001$ ), along with deficits in attention (Digit Span Forwards, $p=0.007$ ) and divided attention (TMT B-A, $p=0.003$ ) relative to Controls. These impairments were not evident in the bvFTD group (all $p$ values $\geq 0.05$ ). Direct comparison of the patient groups revealed disproportionate deficits in visuospatial episodic memory in the AD group relative to the bvFTD group (RCF 3 min: $p=0.005$ ).

Table 2. Descriptive statistics and group differences on neuropsychological tests.

\begin{tabular}{|c|c|c|c|c|c|}
\hline & $\begin{array}{l}\text { bvFTD } \\
\text { M (SD) }\end{array}$ & $\begin{array}{c}\text { AD } \\
M(S D)\end{array}$ & $\begin{array}{l}\text { Controls } \\
\text { M (SD) }\end{array}$ & $\begin{array}{c}\text { Group } \\
\text { Effect }(H)\end{array}$ & $\begin{array}{c}\text { Post Hoc } \\
\text { (Direction of Effect) }\end{array}$ \\
\hline ACE-III Total (100) & $77.7(6.5)$ & $64.8(9.8)$ & $95.3(2.5)$ & $32.8^{* *}$ & $\mathrm{CN}>\mathrm{AD}, \mathrm{bvFTD}$ \\
\hline RAVLT 30 min (15) & $5.2(2.8)$ & $1.1(1.7)$ & $10.8(1.7)$ & $26.9^{* *}$ & $\mathrm{CN}>\mathrm{AD}, \mathrm{bvFTD}$ \\
\hline RCF 3 min (36) & $13.2(6.7)$ & $2.4(2.0)$ & $16.6(4.2)$ & $18.5^{* *}$ & $\mathrm{CN}>\mathrm{AD} ; \mathrm{bvFTD}>\mathrm{AD}$ \\
\hline Hayling Overall (7) & $4.9(1.3)$ & $3.6(0.8)$ & $6.3(0.7)$ & $18.6^{* *}$ & $\mathrm{CN}>\mathrm{AD}, \mathrm{bvFTD}$ \\
\hline Digit Span Forwards & $8.9(2.3)$ & $7.9(0.7)$ & $11.3(2.8)$ & $9.8 *$ & $\mathrm{CN}>\mathrm{AD}$ \\
\hline Digit Span Backwards & $5.1(2.0)$ & $3.7(1.8)$ & $8.3(3.0)$ & $14.1 *$ & $\mathrm{CN}>\mathrm{AD}, \mathrm{bvFTD}$ \\
\hline TMT B-A (seconds) & $82.3(56.7)$ & $142.2(74.2)$ & $45.7(14.9)$ & $11.4 *$ & $\mathrm{CN}<\mathrm{AD}$ \\
\hline SydBat Naming (30) & $24.1(2.3)$ & $19.6(4.9)$ & $27.1(2.3)$ & $16.0^{* *}$ & $\mathrm{CN}>\mathrm{AD}$ \\
\hline SydBat Semantic (30) & $27.0(2.0)$ & $24.3(2.3)$ & $28.6(1.0)$ & $18.8^{* *}$ & $\mathrm{CN}>\mathrm{AD}$ \\
\hline ACE-Language (26) & $23.3(2.5)$ & $21.7(2.8)$ & $25.5(0.8)$ & $18.1^{* *}$ & $\mathrm{CN}>\mathrm{AD}, \mathrm{bvFTD}$ \\
\hline ACE-Fluency (14) & $8.6(2.3)$ & $8.0(2.6)$ & $11.9(1.6)$ & $19.0^{* *}$ & $\mathrm{CN}>\mathrm{AD}, \mathrm{bvFTD}$ \\
\hline
\end{tabular}

Notes. Maximum test scores shown in brackets where appropriate. $\mathrm{M}=$ mean. $\mathrm{SD}=$ standard deviation. Corrected post hoc comparisons shown. ${ }^{*}=p<0.01,{ }^{* *}=p<0.0001$. bvFTD = behavioural-variant frontotemporal dementia; $\mathrm{AD}=$ Alzheimer's disease, $\mathrm{CN}=$ Controls; $\mathrm{ACE}-\mathrm{III}=$ Addenbrooke's Cognitive Examination-Third Edition; RAVLT = Rey Auditory Verbal Learning Test; RCF = Rey Complex Figure; Hayling overall scaled score; TMT B-A = Trail Making Test-Time B minus Time A; SydBat = Sydney Language Battery. Data unavailable for the following tests: RAVLT: 2 CN, 4 AD; RCF: 2 CN, 3 AD; Hayling: 2 CN, 4 AD, 1 bvFTD; TMT B-A: 2 CN, 6 AD, 2 bvFTD.

\subsection{Scene Construction Performance \\ 3.3.1. Total Content}

A significant group effect in terms of content was evident on the scene construction task, $\mathrm{F}(2,39)=53.04, p \leq 0.0001, \eta_{p}{ }^{2}=0.73$. Post hoc tests revealed that total content scores were significantly lower for both AD and bvFTD groups compared to control participants (both $p$ values $\leq 0.0001$ ), with no significant difference between the patient groups $(p=0.481)$. A main effect of sociality, $\mathrm{F}(1,39)=18.58, p \leq 0.0001, \eta_{p}{ }^{2}=0.32$, was also present, with participants performing more poorly overall on social, relative to non-social, scenes $(p \leq 0.0001)$. No main effect of congruency was found, $\mathrm{F}(1,39)=2.53, p=0.120$, $\eta_{p}{ }^{2}=0.06$

A significant group $\times$ sociality $\times$ congruency interaction was observed, $\mathrm{F}(2,39)=3.52$; $p=0.039, \eta_{p}{ }^{2}=0.15$ (Figure 1 ). This was qualified by a significant sociality $\times$ congruency interaction, $\mathrm{F}(1,39)=23.03 ; p \leq 0.0001, \eta_{p}{ }^{2}=0.37$, whereby significantly more content was generated for non-social relative to social scenes in the incongruent condition $(p \leq 0.0001$; congruent: $p=0.417$ ), irrespective of group membership. Closer inspection of the incongruent condition revealed that both patient groups performed significantly better on non-social, relative to social, trials (AD $p=0.002$; bvFTD $p \leq 0.0001$ ). This effect was not observed in the congruent condition (all $p$ values $\geq 0.2$ ). A significant group $\times$ sociality interaction, $\mathrm{F}(2,39)=9.00 ; p=0.001 ; \eta_{p}{ }^{2}=0.32$, was also found. Post hoc tests showed that bvFTD patients generated significantly more detailed non-social, relative to social, scenes $(p \leq 0.0001)$, irrespective of congruency. No such effect was observed for AD patients or 
Controls (both $p$ values $\geq 0.1$ ). Irrespective of sociality, both patient groups performed significantly worse than Controls at each level of congruency (all $p$ values $\leq 0.0001$ ), with no significant difference between the patient groups (both $p$ values $>0.39$ ). Finally, no significant group $\times$ congruency interaction was found, $\mathrm{F}(2,39)=0.14 ; p=0.870 ; \eta_{p}{ }^{2}=0.01$.

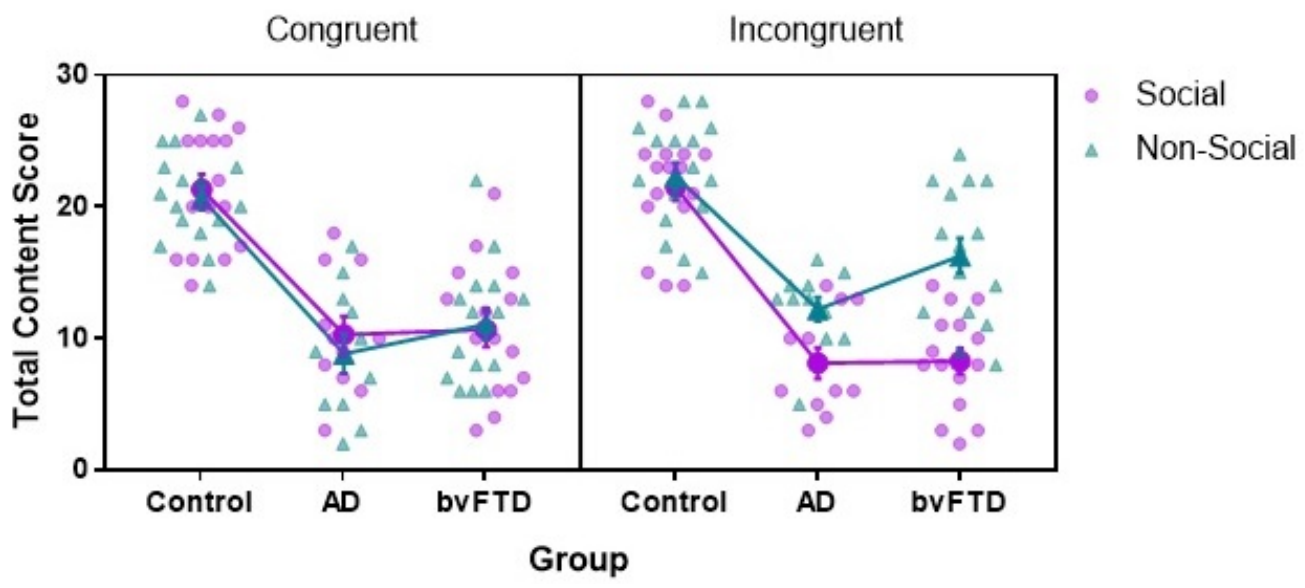

Figure 1. Group performance on social and non-social scene construction in congruent and incongruent conditions. Interaction based on estimated marginal means of average content score ( $\max 28)$ with whiskers representing standard error of measurement. Data points show individual scores. $\mathrm{AD}=$ Alzheimer's disease. bvFTD = behavioural variant of frontotemporal dementia.

\subsubsection{Contextual Detail Profile}

Two mixed $2 \times 4 \times 3$ ANOVAs were performed in the incongruent and congruent conditions separately to examine group differences in contextual details generated across social and non-social conditions. Main effects, interactions and post hoc comparisons are reported for incongruent and congruent analyses separately.

In the incongruent condition, a significant group effect was found, $F(2,39)=42.68$; $p \leq 0.0001, \eta_{p}{ }^{2}=0.69$, with Controls outperforming the AD and bvFTD patient groups (both $p$ values $\leq 0.0001)$ and no difference between the patient groups $(p=0.358)$. A significant main effect of sociality was evident, $F(1,39)=46.46 ; p \leq 0.0001 ; \eta_{p}{ }^{2}=0.54$, whereby scene descriptions were significantly more detailed in non-social, relative to social, scenes $(p \leq 0.0001)$, irrespective of detail type or group membership. Finally, a significant main effect of detail type was found, $F(3,37)=4.54 ; p=0.008 ; \eta_{p}{ }^{2}=0.27$. Relative to the other detail categories, participants produced significantly more unique entities relative to sensory details $(p=0.022)$ and spatial references $(p=0.016)$.

A significant sociality $\times$ group interaction, $F(2,39)=12.67 ; p \leq 0.0001, \eta_{p}{ }^{2}=0.39$, showed that, irrespective of detail type, both patient groups performed significantly better in the non-social, relative to social, condition (AD, $p=0.002$; bvFTD, $p \leq 0.0001$; Figure 2), with no such difference observed in the Control group $(p=0.419)$. Finally, a significant sociality $\times$ detail interaction, $F(3,37)=6.75 ; p=0.001 ; \eta_{p}{ }^{2}=0.35$, reflected the fact that, irrespective of group membership, participants provided more sensory descriptions, spatial references and thoughts, emotions and actions (but not entities present, $p=0.271$ ) in the non-social, relative to social, conditions (all $p$ values $\leq 0.004$ ). The three-way group $\times$ sociality $\times$ detail interaction for incongruent scenes was not significant, $F(6,76)=1.58 ; p=0.166 ; \eta_{p}{ }^{2}=0.11$.

Considering next the congruent condition, a significant group effect was found, $F(2,39)=36.19 ; p \leq 0.0001 ; \eta_{p}{ }^{2}=0.65$, with both AD and bvFTD patient groups performing significantly worse than Controls (both $p$ values $\leq 0.0001$ ), while performance between patient groups was comparable $(p=0.799)$. No significant main effect for sociality emerged, $F(1,39)=0.67 ; p=0.417 ; \eta_{p}{ }^{2}=0.02$; however, a significant main effect of detail was found, $F(3,37)=9.92 ; p \leq 0.0001 ; \eta_{p}{ }^{2}=0.45$. Post hoc comparisons showed that, irrespective of group membership, participants produced significantly more sensory details relative to 
spatial references $(p=0.024)$ and thoughts, emotions, and actions $(p=0.007)$, and more unique entities relative to spatial references $(p=0.008)$.
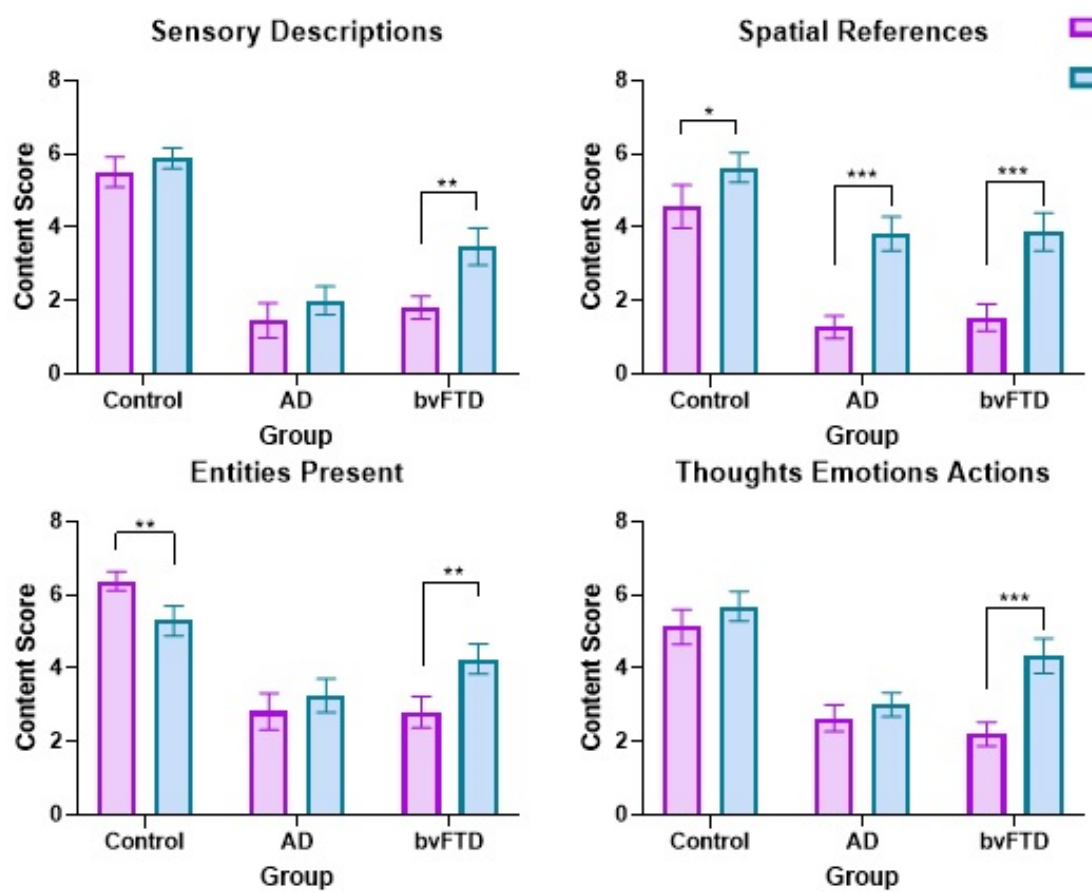

Figure 2. Mean social and non-social scene construction contextual detail scores in the incongruent condition. Whiskers represent standard error of measurement. AD $=$ Alzheimer's disease. bvFTD = behavioural variant of frontotemporal dementia. ${ }^{*}=p<0.05,{ }^{* *}=p<0.01,{ }^{* * *}=p \leq 0.0001$.

Importantly, a significant three-way sociality $\times$ detail $\times$ group interaction was found in the congruent condition, $\mathrm{F}(6,76)=2.63 ; p=0.023 ; \eta_{p}{ }^{2}=0.17$. Post hoc tests showed that AD patients provided significantly fewer entities present in the non-social, relative to the social, condition $(p=0.009)$, with a similar trend observed for spatial references $(p=0.055$, Figure 3$)$. No other significant differences in content scores were present between social and non-social conditions in any of the groups (all $p$ values $\geq 0.2$ ). None of the two-way interactions were significant: sociality $\times$ group, $F(2,39)=0.55 ; p=0.579 ; \eta_{p}{ }^{2}=0.03$, sociality $\times$ detail, $F(3,37)=1.09 ; p=0.364 ; \eta_{p}{ }^{2}=0.08$, detail $\times$ group, $F(6,76)=1.39 ; p=0.230 ; \eta_{p}{ }^{2}=0.10$.

\subsubsection{Participant Subjective Ratings}

We next explored whether participant subjective ratings differed according to the social nature of the constructed scene and the congruency of scene-object cues. Independent samples Kruskal-Wallis tests failed to reveal any significant group differences in terms of subjective ratings of overall difficulty, vividness, level of detail, sense of presence, perceived realism, or similarity to a previous memory (all $p$ values $\geq 0.19$ ).

Two sets of Wilcoxon signed-rank tests were used to explore phenomenological differences in the construction of social and non-social scene types within each group separately (Table 3). BvFTD $(Z=-2.52, p=0.012)$ and $\operatorname{AD}(Z=-2.23, p=0.026)$ patients rated the construction of social scenes based on congruent scene-object pairs as more similar to a previous memory than scenes based on incongruent pairings. The bvFTD group further rated the construction of social scenes based on incongruent scene-object pairs as more difficult compared to congruent pairs $(Z=-2.23, p=0.026)$. All participant groups rated the construction of non-social scenes based on congruent scene-object pairs as more similar to a previous memory than those based on incongruent scene-object pairs (bvFTD: $Z=-2.70$, $p=0.007$; AD: $Z=-2.23, p=0.026$; Control: $Z=-2.72, p=0.006$ ). No other comparisons were significant (all $p$ values $\geq 0.07$ ). 


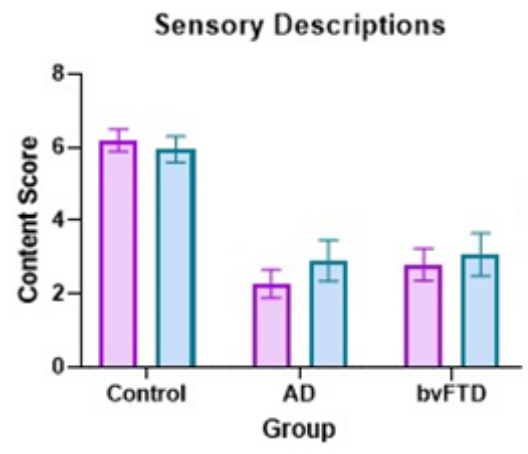

Entities Present

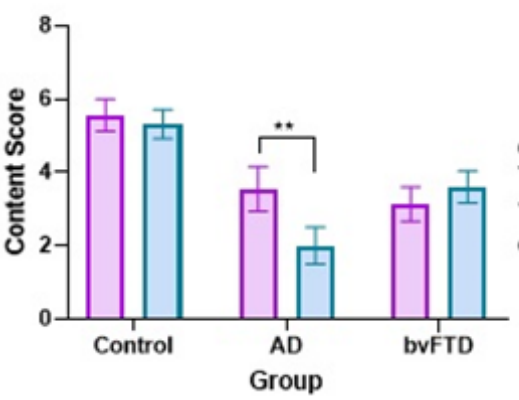

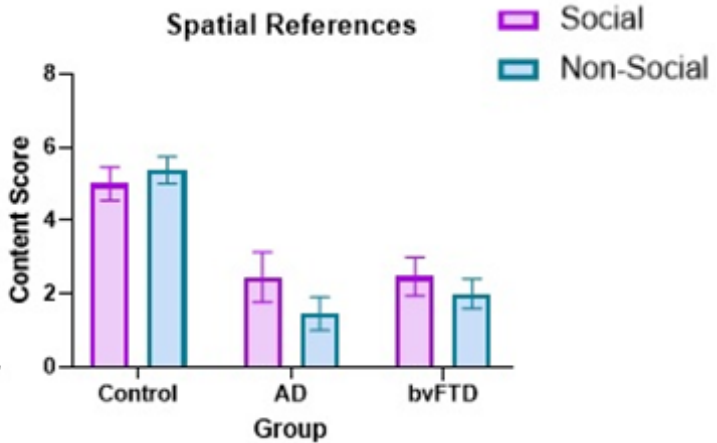

Thoughts Emotions Actions

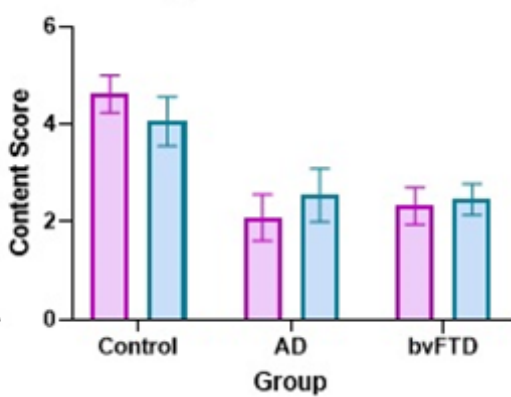

Figure 3. Mean social and non-social scene construction contextual detail scores in the congruent condition. Whiskers represent standard error of measurement. AD = Alzheimer's disease. bvFTD = behavioural variant of frontotemporal dementia. ${ }^{* *}=p<0.01$.

Table 3. Subjective ratings for each condition in participant groups.

\begin{tabular}{|c|c|c|c|c|c|}
\hline & & & $\begin{array}{l}\text { bvFTD } \\
\text { M (SD) }\end{array}$ & $\begin{array}{c}\text { AD } \\
M(S D)\end{array}$ & $\begin{array}{l}\text { Control } \\
\mathrm{M} \text { (SD) }\end{array}$ \\
\hline \multirow[t]{4}{*}{ Difficulty } & \multirow[t]{2}{*}{ Congruent } & Social & $2.1(0.9)$ & $2.5(0.9)$ & $2.2(1.1)$ \\
\hline & & Non-Social & $2.9(1.1)$ & $2.6(1.1)$ & $2.3(0.9)$ \\
\hline & \multirow[t]{2}{*}{ Incongruent } & Social & $3.0(1.1)$ & $2.7(1.0)$ & $2.4(1.0)$ \\
\hline & & Non-Social & $2.7(1.2)$ & $3.4(1.1)$ & $2.6(1.3)$ \\
\hline \multirow[t]{4}{*}{ Vividness } & \multirow{2}{*}{ Congruent } & Social & $3.2(0.9)$ & $3.6(0.7)$ & $3.7(0.8)$ \\
\hline & & Non-Social & $3.1(1.0)$ & $3.5(0.7)$ & $3.6(1.0)$ \\
\hline & \multirow[t]{2}{*}{ Incongruent } & Social & $3.1(1.1)$ & $3.1(0.9)$ & $3.6(1.0)$ \\
\hline & & Non-Social & $3.3(1.0)$ & $3.6(0.9)$ & $3.3(1.1)$ \\
\hline \multirow{4}{*}{ Level of Detail } & \multirow{2}{*}{ Congruent } & Social & $3.3(0.9)$ & $2.9(0.8)$ & $3.4(0.8)$ \\
\hline & & Non-Social & $3.1(1.0)$ & $2.7(0.8)$ & $3.4(0.8)$ \\
\hline & \multirow[t]{2}{*}{ Incongruent } & Social & $3.0(1.1)$ & $2.7(0.6)$ & $3.3(0.8)$ \\
\hline & & Non-Social & $3.4(1.0)$ & $2.9(0.9)$ & $3.0(0.9)$ \\
\hline \multirow{4}{*}{ Sense of Presence } & \multirow{2}{*}{ Congruent } & Social & $3.5(0.9)$ & $4.0(0.6)$ & $3.9(1.0)$ \\
\hline & & Non-Social & $3.2(1.1)$ & $3.5(0.8)$ & $3.6(1.1)$ \\
\hline & \multirow[t]{2}{*}{ Incongruent } & Social & $3.1(1.1)$ & $3.4(0.9)$ & $3.5(1.1)$ \\
\hline & & Non-Social & $3.3(1.2)$ & $3.9(0.9)$ & $3.4(1.1)$ \\
\hline \multirow[t]{4}{*}{ Realism } & \multirow[t]{2}{*}{ Congruent } & Social & $3.1(1.0)$ & $3.1(0.6)$ & $3.3(1.1)$ \\
\hline & & Non-Social & $2.9(0.9)$ & $3.3(0.9)$ & $3.4(1.0)$ \\
\hline & \multirow[t]{2}{*}{ Incongruent } & Social & $3.1(1.1)$ & $3.4(0.9)$ & $3.5(1.1)$ \\
\hline & & Non-Social & $3.3(1.2)$ & $3.9(0.9)$ & $3.4(1.1)$ \\
\hline \multirow{4}{*}{ Similar to Memory } & \multirow{2}{*}{ Congruent } & Social & $2.8(1.1)$ & $2.6(1.5)$ & $3.3(1.0)$ \\
\hline & & Non-Social & $3.1(1.3)$ & $2.4(0.8)$ & $3.1(1.1)$ \\
\hline & \multirow[t]{2}{*}{ Incongruent } & Social & $4.0(1.0)$ & $4.0(1.1)$ & $3.9(1.4)$ \\
\hline & & Non-Social & $4.3(0.8)$ & $3.8(1.1)$ & $4.1(1.4)$ \\
\hline
\end{tabular}

Notes. $\mathrm{M}=$ mean. $\mathrm{SD}$ = standard deviation. For all ratings higher scores = stronger perceived experience, i.e., greater difficulty; more vividness; richer detail; more realistic; except similarity to memory where lower scores = more similar to a previous memory. bvFTD = behavioural variant of frontotemporal dementia. AD = Alzheimer's disease.

\subsection{Correlations between Scene Construction and Selected Cognitive Variables}

One-tailed Pearson correlations were run to explore potential associations between Total Content generated for each condition and performance on selected measures of cognitive function in the patient groups combined $(n=23$; see Table 4$)$. Measures of semantic 
processing on the SydBat were moderately associated with congruent and incongruent non-social scene construction (all $r$ values $\geq 0.3$ ), while response inhibition was associated with congruent social scene construction. Delayed visuospatial episodic recall (RCF 3 min recall) was found to correlate with non-social scene construction performance in both the congruent and incongruent conditions (all $\mathrm{r}$ values $\geq 0.4$ ).

Table 4. Pearson correlation coefficients exploring associations between scene construction performance and cognitive variables in AD and bvFTD groups combined $(n=23)$.

Total Content Scores

\begin{tabular}{ccccc}
\hline & \multicolumn{2}{c}{ Congruent } & \multicolumn{2}{c}{ Incongruent } \\
\hline & Social & Non-Social & Social & Non-Social \\
\hline SydBat Semantic Association & 0.237 & $0.391^{*}$ & 0.005 & $0.483^{*}$ \\
SydBat Semantic Naming & -0.181 & $0.427^{*}$ & 0.014 & 0.331 \\
RCF 3 min recall & 0.347 & $0.411^{*}$ & 0.214 & $0.528^{* *}$ \\
Hayling Overall Scaled & $0.393^{*}$ & 0.275 & 0.129 & 0.333 \\
RAVLT 30 min recall & -0.143 & 0.090 & 0.261 & 0.177 \\
\hline
\end{tabular}

Notes. Uncorrected one-tailed Pearson correlation coefficients. ${ }^{*}=p<0.05^{* *}=p \leq 0.01$. Patient numbers within each test: SydBat $=$ Sydney Language Battery, $\mathrm{AD}=11$, bvFTD $=9 ; \mathrm{RCF}=$ Rey Complex Figure, $\mathrm{AD}=8$, $\mathrm{bvFTD}=15$; Hayling, $\mathrm{AD}=6$, bvFTD = 14; RAVLT = Rey Auditory Verbal Learning Test, $\mathrm{AD}=7, \mathrm{bvFTD}=15$.

\section{Discussion}

The objective of this study was to explore how schema congruency influences the generation of contextual details and the accompanying subjective experience during scene construction in dementia. Using a novel extension of the classic scene construction paradigm, we manipulated the congruency of scene-object cues across social and non-social contexts. Overall, we observed differential effects of congruency on the capacity for social versus non-social scene construction, with incongruent social scenes disproportionately affected in dementia. This effect was not observed in the congruent condition, with comparable performance across social and non-social trials within each group. We consider the potential underlying mechanisms that drive disproportionate impairments in the construction of incongruent social scenes as well as possible clinical implications of such impairments for people with dementia.

The most striking finding in this study is our observation of profound impairments in the construction of social scenes that require the integration of incongruent scene-object cues. Previous studies have demonstrated a grossly diminished capacity for mental construction in bvFTD spanning episodic and autobiographical memory [53-56], episodic and semantic forms of future simulation [34,57], and the construction of commonplace atemporal scenes [35]. Importantly, we replicated our previous finding of markedly compromised social relative to non-social scene construction in bvFTD [26], but extended these findings by considering the modulating role of scene-object congruency on the constructive endeavour. Within-group analyses revealed that bvFTD patients generated significantly fewer contextual details on social relative to non-social trials, most pronounced for the incongruent condition. This finding indicates a specific impairment in the construction of social scenes, which call for the integration of elements that are incompatible with existing schemas. Notably, bvFTD patients subjectively rated incongruent social scenes as more difficult to construct relative to congruent social scenes, suggesting a convergence between objective task performance and phenomenology in this group.

We tentatively interpret these findings as reflecting the higher integrative load of the incongruent social condition, whereby participants are required to combine two semantically unrelated items (e.g., clown, funeral) that are highly unlikely to co-occur within the same social context. Previous work suggests that increasing the constructive demands of future simulation tasks is associated with significantly reduced episodic detail in older adults [58]. Using a novel experimental task, Addis and colleagues manipulated the recombinatorial load of stimulus sets comprising person, place, and object details for past 
and future conditions. Events requiring the integration of person, place, and object details taken from three separate events were found to be less detailed and less rich in terms of phenomenology in older adults. Moreover, events simulated under high recombinatorial load were rated as less similar to previous memories, suggesting the events generated were highly novel and not likely to have been previously experienced [58]. Looking at the similarity to past memory ratings provided by participants in the current study, we found that congruent social scenes were rated by bvFTD and AD patients as more similar to a previous memory than incongruent social scenes. It may be that congruent social scenes (in this case "doctor- hospital") more readily evoke well-defined event scripts (e.g., what usually happens in the hospital) or personally experienced memories ("the last time I was in hospital") that support the construction of a unified spatial array [59-61]. In contrast, incongruent scenes ("clown-funeral") require the integration of details that do not typically coincide within a given spatial or social context, thus precluding the ability to draw upon previous experiences. Such novel events have been shown to rely more heavily upon semantic, rather than episodic, memory [62], suggesting a compensatory mechanism when episodic content is low [63].

Our correlation analyses revealed significant associations between the construction of congruent and incongruent non-social scenes in the combined patient group and independent measures of semantic processing and delayed visuospatial episodic recall. The semantic association task measures the capacity to bridge disparate semantic concepts via an appropriate semantic link, providing an index of semantic relational processing, while the visuospatial task assesses delayed episodic memory retrieval for non-verbal material. Our finding of comparable associations between semantic and episodic neuropsychological tasks with non-social scene construction converges with current theoretical positions emphasising the interplay between the episodic and semantic memory systems in the rendering of detailed spatial arrays [60]. Notably, we did not find these associations in the social conditions. Rather, socially congruent scene construction was found to correlate exclusively with response inhibition, suggesting a possible role for the suppression of details that do not fit within a given social context. We tentatively propose that the incongruent social condition represents a recombinatorial step too far for patients with dementia, requiring the integration of disparate elements not typically co-located within the same spatial setting or social scenario, in the absence of a suitable event script or schema.

A number of methodological issues warrant consideration in this context. To avoid fatigue in the dementia patients, we limited our study to one trial per condition, thus reducing overall study power. Given our relatively small sample size, we did not run the correlation analyses in the bvFTD and AD groups separately, limiting our capacity to comment on the mechanisms that potentially drive scene construction impairments in these disorders. Future studies in a larger sample of dementia patients, stratified by disease severity, with a greater number of experimental trials will be required to replicate the current findings. Similarly, to ensure a shorter testing time, we opted not to include the Spatial Coherence Index from the original scene construction task. Inclusion of the Spatial Coherence Index would further enable us to determine how manipulations of sociality and congruency influence the spatial cohesion of the constructed scene.

\section{Conclusions}

Our study provides initial clues as to how object-scene (in)congruency impacts the capacity for scene construction in dementia. Despite largely comparable scene construction performance profiles in bvFTD and AD, we suggest that the cognitive and neural mechanisms driving these impairments are likely to differ. For example, constructive deficits in AD might arise due to characteristic episodic and semantic memory disturbances, alongside visuospatial dysfunction [64,65], while deficits in bvFTD might be better explained by socioemotional and executive disturbances that typify this syndrome $[32,66]$. As we did not include targeted measures of social cognition or emotion processing in this study, future studies will be required to definitively test these proposals. It will also be important 
to explore how the impairments uncovered in this study relate to social cognitive and behavioural changes, such as apathy, increased mental rigidity and environmental dependency, particularly in bvFTD $[67,68]$. Finally, we suggest that studies exploring the neural correlates of these disturbances will be important to clarify the respective contribution of key structures implicated in mental construction, most notably the hippocampus and ventromedial prefrontal cortex $[30,69]$. Addressing these questions will provide important insights regarding the multifaceted processes which enable us to envisage contextually rich scene imagery and how such processes break down in dementia.

Supplementary Materials: The following are available online at https: / www.mdpi.com/article / 10.3390/brainsci12010020/s1, Supplementary Material: Table S1: Pilot ratings of item congruence for scene-object cues on the modified scene construction task; Supplementary Material 2: Sample scene description provided to participants by the experimenter; Supplementary Material 3: Prompting instructions provided to participants during scene construction.

Author Contributions: Conceptualisation: N.-A.W., O.P. and M.I.; Data curation: N.-A.W., R.M.A.; Formal analysis: N.-A.W., M.I., Funding acquisition, O.P., Methodology: N.-A.W. and M.I.; Resources: O.P., Supervision: M.I. and O.P. Writing-original draft preparation: N.-A.W. and M.I., Writingreview and editing: M.I., R.M.A. and O.P. All authors have read and agreed to the published version of the manuscript.

Funding: This work was supported in part by funding to ForeFront, a large collaborative research group dedicated to the study of neurodegenerative diseases, from the National Health and Medical Research Council of Australia (NHMRC) Program grant (GNT1132524), Dementia Research Team Grant (GNT1095127) and the Australian Research Council Centre of Excellence in Cognition and its Disorders Memory Program (CE110001021). RMA is an NHMRC Early Career Fellow (GNT1120770). OP is an NHMRC Senior Research Fellow (GNT1103258). MI is supported by an Australian Research Council (ARC) Future Fellowship (FT160100096) and an ARC Discovery Project (DP180101548). These funding sources were not involved in the study design, in the collection, analysis and interpretation of data, in the writing of the report, or in the decision to submit the manuscript for publication.

Institutional Review Board Statement: This study was conducted according to the guidelines of the Declaration of Helsinki, and approved by the University of New South Wales and South Eastern Sydney Local Health District Human Ethics Committee (HREC 10/126).

Informed Consent Statement: Informed consent was obtained from all participants involved in this study. Written informed consent has been obtained from the patient(s) to publish this paper.

Data Availability Statement: The ethical requirement to ensure patient confidentiality precludes public archiving of our data. Researchers who would like to access the raw data should contact the corresponding author, who will liaise with the ethics committee that approved the study. Accordingly, as much data as are required to reproduce the results will be released to the individual researcher. No parts of the study procedures or analyses were registered prior to the research being undertaken.

Acknowledgments: The authors are grateful to the research participants involved with the ForeFront research studies. We wish to thank John R. Hodges for helpful comments, and Hashim El-Omar, Sau Chi Cheung, and Samuel Stark for their research assistance.

Conflicts of Interest: The authors report no conflict of interest.

\section{References}

1. Hassabis, D.; Kumaran, D.; Maguire, E.A. Using imagination to understand the neural basis of episodic memory. J. Neurosci. 2007, 27, 14365-14374. [CrossRef] [PubMed]

2. Hassabis, D.; Maguire, E.A. The construction system of the brain. Philos. Trans. R. Soc. Lond. B Biol. Sci. 2009, 364, 1263-1271. [CrossRef] [PubMed]

3. Maguire, E.A.; Intraub, H.; Mullally, S.L. Scenes, Spaces, and Memory Traces: What Does the Hippocampus Do? Neuroscientist 2016, 22, 432-439. [CrossRef] [PubMed]

4. Hebscher, M.; Levine, B.; Gilboa, A. The precuneus and hippocampus contribute to individual differences in the unfolding of spatial representations during episodic autobiographical memory. Neuropsychologia 2018, 110, 123-133. [CrossRef]

5. $\quad$ Palombo, D.J.; Hayes, S.M.; Peterson, K.M.; Keane, M.M.; Verfaellie, M. Medial Temporal Lobe Contributions to Episodic Future Thinking: Scene Construction or Future Projection? Cereb. Cortex 2018, 28, 447-458. [CrossRef] 
6. Lind, S.E.; Williams, D.M.; Bowler, D.M.; Peel, A. Episodic memory and episodic future thinking impairments in high-functioning autism spectrum disorder: An underlying difficulty with scene construction or self-projection? Neuropsychology 2014, 28 , 55-67. [CrossRef]

7. Gaesser, B. Episodic mindreading: Mentalizing guided by scene construction of imagined and remembered events. Cognition 2020, 203, 104325. [CrossRef]

8. Mullally, S.L.; Maguire, E.A. Memory, Imagination, and Predicting the Future: A Common Brain Mechanism? Neuroscientist 2014, 20, 220-234. [CrossRef]

9. Mullally, S.; Hassabis, D.; Maguire, E.A. Scene construction in amnesia: An fMRI study. J. Neurosci. 2012, 32, 5646-5653. [CrossRef]

10. Kim, S.; Dede, A.J.O.; Hopkins, R.O.; Squire, L.R. Memory, scene construction, and the human hippocampus. Proc. Natl. Acad. Sci. USA 2015, 112, 4767-4772. [CrossRef]

11. Cooper, J.M.; Vargha-Khadem, F.; Gadian, D.G.; Maguire, E.A. The effect of hippocampal damage in children on recalling the past and imagining new experiences. Neuropsychologia 2011, 49, 1843-1850. [CrossRef] [PubMed]

12. Hurley, N.C.; Maguire, E.A.; Vargha-Khadem, F. Patient HC with developmental amnesia can construct future scenarios. Neuropsychologia 2011, 49,3620-3628. [CrossRef]

13. Irish, M. On the interaction between episodic and semantic representations-Constructing a unified account of imagination. In The Cambridge Handbook of the Imagination; Abraham, A., Ed.; Cambridge University Press: New York, NY, USA, 2020; pp. 447-465.

14. Addis, D.R. Are episodic memories special? On the sameness of remembered and imagined event simulation. J. R. Soc. N. Z. 2018, 48, 64-88. [CrossRef]

15. Irish, M.; Addis, D.R.; Hodges, J.R.; Piguet, O. Considering the role of semantic memory in episodic future thinking: Evidence from semantic dementia. Brain 2012, 135, 2178-2191. [CrossRef] [PubMed]

16. Irish, M.; Piguet, O. The pivotal role of semantic memory in remembering the past and imagining the future. Front. Behav. Neurosci. 2013, 7, 27. [CrossRef]

17. Abraham, A.; Bubic, A. Semantic memory as the root of imagination. Front. Psychol. 2015, 6, 1-5. [CrossRef]

18. Renoult, L.; Irish, M.; Moscovitch, M.; Rugg, M.D. From Knowing to Remembering: The Semantic-Episodic distinction. Trends Cogn. Sci. 2019, 23, 1041-1057. [CrossRef] [PubMed]

19. Irish, M. Semantic memory as the essential scaffold for future oriented mental time travel. In Seeing the Future: Theoretical Perspectives on Future-Oriented Mental Time Travel; Michaelian, K., Klein, S.B., Szpunar, K., Eds.; Oxford University Press: New York, NY, USA, 2016; pp. 388-408.

20. Paulin, T.; Roquet, D.; Kenett, Y.N.; Savage, G.; Irish, M. The effect of semantic memory degeneration on creative thinking: A voxel-based morphometry analysis. Neuroimage 2020, 220, 117073. [CrossRef] [PubMed]

21. Kenett, Y.N.; Faust, M. A Semantic Network Cartography of the Creative Mind. Trends Cogn. Sci. 2019, 23, 271-274. [CrossRef]

22. Summerfield, J.J.; Hassabis, D.; Maguire, E.A. Differential engagement of brain regions within a 'core' network during scene construction. Neuropsychologia 2010, 48, 1501-1509. [CrossRef]

23. Dalton, M.A.; Zeidman, P.; McCormick, C.; Maguire, E.A. Differentiable Processing of Objects, Associations, and Scenes within the Hippocampus. J. Neurosci. 2018, 38, 8146-8159. [CrossRef] [PubMed]

24. Mullally, S.; Maguire, E. Exploring the role of space-defining objects in constructing and maintaining imagined scenes. Brain Cogn. 2013, 82, 100-107. [CrossRef] [PubMed]

25. Hassabis, D.; Spreng, R.N.; Rusu, A.A.; Robbins, C.A.; Mar, R.A.; Schacter, D.L. Imagine all the people: How the brain creates and uses personality models to predict behavior. Cereb. Cortex 2014, 24, 1979-1987. [CrossRef] [PubMed]

26. Wilson, N.A.; Ahmed, R.M.; Hodges, J.R.; Piguet, O.; Irish, M. Constructing the social world: Impaired capacity for social simulation in dementia. Cognition 2020, 202, 104321. [CrossRef]

27. Gaesser, B.; Schacter, D.L. Episodic simulation and episodic memory can increase intentions to help others. Proc. Natl. Acad. Sci. USA 2014, 111, 4415-4420. [CrossRef] [PubMed]

28. Gilboa, A.; Marlatte, H. Neurobiology of Schemas and Schema-Mediated Memory. Trends Cogn. Sci. 2017, 21, 618-631. [CrossRef] [PubMed]

29. Irish, M.; van Kesteren, M.T. New Perspectives on the Brain Lesion Approach-Implications for Theoretical Models of Human Memory. Neuroscience 2018, 374, 319-322. [CrossRef]

30. Ciaramelli, E.; Luca, F.D.; Monk, A.M.; McCormick, C.; Maguire, E.A. What "wins" in vmPFC: Scenes, situations, or schema? Neurosci. Biobehav. Rev. 2019, 100, 208-210. [CrossRef]

31. Van Kesteren, M.T.; Ruiter, D.J.; Fernandez, G.; Henson, R.N. How schema and novelty augment memory formation. Trends Neurosci. 2012, 35, 211-219. [CrossRef]

32. Rascovsky, K.; Hodges, J.R.; Knopman, D.; Mendez, M.F.; Kramer, J.H.; Neuhaus, J.; van Swieten, J.C.; Seelaar, H.; Dopper, E.G.; Onyike, C.U.; et al. Sensitivity of revised diagnostic criteria for the behavioural variant of frontotemporal dementia. Brain 2011, 134, 2456-2477. [CrossRef]

33. Irish, M.; Piguet, O.; Hodges, J.R. Self-projection and the default network in frontotemporal dementia. Nat. Rev. Neurol. 2012, 8, 152-161. [CrossRef]

34. Irish, M.; Hodges, J.R.; Piguet, O. Episodic future thinking is impaired in the behavioural variant of frontotemporal dementia. Cortex 2013, 49, 2377-2388. [CrossRef] [PubMed] 
35. Wilson, N.A.; Ramanan, S.; Roquet, D.; Goldberg, Z.L.; Hodges, J.R.; Piguet, O.; Irish, M. Scene construction impairments in frontotemporal dementia: Evidence for a primary hippocampal contribution. Neuropsychologia 2020, 137, 107327. [CrossRef]

36. McKhann, G.M.; Knopman, D.S.; Chertkow, H.; Hyman, B.T.; Jack, C.R., Jr.; Kawas, C.H.; Klunk, W.E.; Koroshetz, W.J.; Manly, J.J.; Mayeux, R.; et al. The diagnosis of dementia due to Alzheimer's disease: Recommendations from the National Institute on Aging-Alzheimer's Association workgroups on diagnostic guidelines for Alzheimer's disease. Alzheimers Dement. 2011, 7, 263-269. [CrossRef] [PubMed]

37. Irish, M.; Addis, D.R.; Hodges, J.R.; Piguet, O. Exploring the content and quality of episodic future simulations in semantic dementia. Neuropsychologia 2012, 50, 3488-3495. [CrossRef] [PubMed]

38. Addis, D.R.; Sacchetti, D.C.; Ally, B.A.; Budson, A.E.; Schacter, D.L. Episodic simulation of future events is impaired in mild Alzheimer's disease. Neuropsychologia 2009, 47, 2660-2671. [CrossRef]

39. Irish, M.; Halena, S.; Kamminga, J.; Tu, S.; Hornberger, M.; Hodges, J.R. Scene construction impairments in Alzheimer's disease-A unique role for the posterior cingulate cortex. Cortex 2015, 73, 10-23. [CrossRef]

40. Dermody, N.; Wong, S.; Ahmed, R.; Piguet, O.; Hodges, J.R.; Irish, M. Uncovering the Neural Bases of Cognitive and Affective Empathy Deficits in Alzheimer's Disease and the Behavioral-Variant of Frontotemporal Dementia. J. Alzheimers Dis. 2016, 53, 801-816. [CrossRef]

41. Strikwerda-Brown, C.; Ramanan, S.; Irish, M. Neurocognitive mechanisms of theory of mind impairment in neurodegeneration: A transdiagnostic approach. Neuropsychiatr. Dis. Treat. 2019, 15, 557-573. [CrossRef]

42. Knopman, D.S.; Kramer, J.H.; Boeve, B.F.; Caselli, R.J.; Graff-Radford, N.R.; Mendez, M.F.; Miller, B.L.; Mercaldo, N. Development of methodology for conducting clinical trials in frontotemporal lobar degeneration. Brain 2008, 131, 2957-2968. [CrossRef]

43. Wear, H.J.; Wedderburn, C.J.; Mioshi, E.; Williams-Gray, C.H.; Mason, S.L.; Barker, R.A.; Hodges, J.R. The Cambridge Behavioural Inventory revised. Dement. Neuropsychol. 2008, 2, 102-107. [CrossRef] [PubMed]

44. Hsieh, S.; Schubert, S.; Hoon, C.; Mioshi, E.; Hodges, J.R. Validation of the Addenbrooke's Cognitive Examination III in frontotemporal dementia and Alzheimer's disease. Dement. Geriatr. Cogn. Disord. 2013, 36, 242-250. [CrossRef] [PubMed]

45. So, M.; Foxe, D.; Kumfor, F.; Murray, C.; Hsieh, S.; Savage, G.; Ahmed, R.M.; Burrell, J.R.; Hodges, J.R.; Irish, M.; et al. Addenbrooke's Cognitive Examination III: Psychometric Characteristics and Relations to Functional Ability in Dementia. J. Int. Neuropsychol. Soc. 2018, 24, 854-863. [CrossRef] [PubMed]

46. Schmidt, M. Rey Auditory and Verbal Learning Test: A handbook; Western Psychological Services: Los Angeles, CA, USA, 1996.

47. Rey, A. L'examen psychologique dans les cas d'encéphalopathie traumatique. Arch. Psychol. 1941, $28,215-285$.

48. Savage, S.; Hsieh, S.; Piguet, O.; Hodges, J.R.; Leslie, F.; Foxe, D.; Piguet, O.; Hodges, J.R.; Leslie, F.; Foxe, D. Distinguishing subtypes in primary progressive aphasia: Application of the Sydney Language Battery. Dement. Geriatr. Cogn. Disord. 2013, 35 , 208-218. [CrossRef]

49. Wechsler, D. Wechsler Memory Scale-Third Edition: Administration and Scoring Manual; Psychological Corporation: San Antonio, TX, USA, 1997.

50. Reitan, R. Validity of the Trail Making Test as an indicator of organic brain damage. Percept. Mot. Ski. 1958, 8, 271-276. [CrossRef]

51. Burgess, P.W.; Shallice, T. The Hayling and Brixton Tests; Thames Valley Test Company: Thurston Suffolk, UK, 1997.

52. Hassabis, D.; Kumaran, D.; Vann, S.D.; Maguire, E.A. Patients with hippocampal amnesia cannot imagine new experiences. Proc. Natl. Acad. Sci. USA 2007, 104, 1726-1731. [CrossRef]

53. Irish, M.; Hornberger, M.; Lah, S.; Miller, L.; Pengas, G.; Nestor, P.J.; Hodges, J.R.; Piguet, O. Profiles of recent autobiographical memory retrieval in semantic dementia, behavioural-variant frontotemporal dementia, and Alzheimer's disease. Neuropsychologia 2011, 49, 2694-2702. [CrossRef]

54. Irish, M.; Landin-Romero, R.; Mothakunnel, A.; Ramanan, S.; Hsieh, S.; Hodges, J.R.; Piguet, O. Evolution of autobiographical memory impairments in Alzheimer's disease and frontotemporal dementia-A longitudinal neuroimaging study. Neuropsychologia 2018, 110, 14-25. [CrossRef]

55. Piolino, P.; Chételat, G.; Matuszewski, V.; Landeau, B.; Mézenge, F.; Viader, F.; De La Sayette, V.; Eustache, F.; Desgranges, B. In search of autobiographical memories: A PET study in the frontal variant of frontotemporal dementia. Neuropsychologia 2007, 45, 2730-2743. [CrossRef]

56. Irish, M.; Piguet, O.; Hodges, J.R.; Hornberger, M. Common and unique grey matter correlates of episodic memory dysfunction in frontotemporal dementia and Alzheimer's disease. Hum. Brain Mapp. 2014, 35, 1422-1435. [CrossRef]

57. Irish, M.; Eyre, N.; Dermody, N.; O'Callaghan, C.; Hodges, J.R.; Hornberger, M.; Piguet, O. Neural Substrates of Semantic Prospection-Evidence from the Dementias. Front. Behav. Neurosci. 2016, 10, 96. [CrossRef] [PubMed]

58. Addis, D.R.; Musicaro, R.; Pan, L.; Schacter, D.L. Episodic simulation of past and future events in older adults: Evidence from an experimental recombination task. Psychol. Aging 2010, 25, 369-376. [CrossRef]

59. Robin, J.; Moscovitch, M. Details, gist and schema: Hippocampal-neocortical interactions underlying recent and remote episodic and spatial memory. Curr. Opin. Behav. Sci. 2017, 17, 114-123. [CrossRef]

60. Rubin, D.C.; Umanath, S. Event memory: A theory of memory for laboratory, autobiographical, and fictional events. Psychol. Rev. 2015, 122, 1-23. [CrossRef] [PubMed]

61. Irish, M.; Mothakunnel, A.; Dermody, N.; Wilson, N.A.; Hodges, J.R.; Piguet, O. Damage to right medial temporal structures disrupts the capacity for scene construction-A case study. Hippocampus 2017, 27, 635-641. [CrossRef] [PubMed] 
62. Wang, T.; Yue, T.; Huang, X.T. Episodic and Semantic Memory Contribute to Familiar and Novel Episodic Future Thinking. Front. Psychol. 2016, 7, 1746. [CrossRef]

63. Devitt, A.L.; Addis, D.R.; Schacter, D.L. Episodic and semantic content of memory and imagination: A multilevel analysis. Mem. Cogn. 2017, 45, 1078-1094. [CrossRef]

64. Irish, M.; Piolino, P. Impaired capacity for prospection in the dementias-Theoretical and clinical implications. Br. J. Clin. Psychol. 2016, 55, 49-68. [CrossRef]

65. Salimi, S.; Irish, M.; Foxe, D.; Hodges, J.R.; Piguet, O.; Burrell, J.R. Can visuospatial measures improve the diagnosis of Alzheimer's disease? Alzheimers Dement. 2018, 10, 66-74. [CrossRef]

66. Strikwerda-Brown, C.; Ramanan, S.; Goldberg, Z.L.; Mothakunnel, A.; Hodges, J.R.; Ahmed, R.M.; Piguet, O.; Irish, M. The interplay of emotional and social conceptual processes during moral reasoning in frontotemporal dementia. Brain 2021, 144, 938-952. [CrossRef]

67. O'Callaghan, C.; Shine, J.M.; Hodges, J.R.; Andrews-Hanna, J.R.; Irish, M. Hippocampal atrophy and intrinsic brain network dysfunction relate to alterations in mind wandering in neurodegeneration. Proc. Natl. Acad. Sci. USA 2019, 116, $3316-3321$. [CrossRef] [PubMed]

68. Shaw, S.R.; El-Omar, H.; Roquet, D.; Hodges, J.R.; Piguet, O.; Ahmed, R.M.; Whitton, A.E.; Irish, M. Uncovering the prevalence and neural substrates of anhedonia in frontotemporal dementia. Brain 2021, 5, 1551-1564. [CrossRef] [PubMed]

69. Conti, F.; Irish, M. Harnessing visual imagery and oculomotor behaviour to understand prospection. Trends Cogn. Sci. 2021, $25,272-283$. 